\title{
A BAGACEIRA ENTRE TEMPOS
}

\author{
José Carlos Garbuglio
}

Um estudo que não pretenda cometer injustiças ao examinar A Bagaceira tem de levar em conta as duas coordenadas básicas em que se movimenta o romance: a histórica e a estética. Isto significa considerar as circunstâncias em que apareceu, sua situação nos quadros da Literatura Brasileira, para apreciando-o em relação diacrônica, poder ajuizá-lo em sua importância histórica, enquanto se define seu lugar e valor como produto estético.

Quando apareceu, em 1928, A Bagaceira veio preencher um sensível vazio na ficção brasileira da época. Se de um lado atendia de perto as propostas regionalistas que aguardavam realização, respondia também aos anseios modernistas, cumpria algumas daquelas expectativas e gerava outras. Estava-se à procura de rumos, direções que pudessem orientar o aproveitamento de novas vertentes ficcionais capazes de encampar as propostas em curso, funcionar como estímulo para sacudir e mesmo revitalizar o ambiente literário.

A pressuposição de que o romance de José Américo de Almeida tenha atendido a este tipo de espera, coroando as expectativas, talvez explique a euforia com que Tristão de Ataíde saudou seu aparecimento, no fogo do instante, vendo nele obra plenamente realizada, o romance ansiosamente aguardado, depois do longo intervalo de marasmo na ficção brasileira.

Tendo-se em vista as condições especiais do momento, entende-se a ênfase do crítico que intencionalmente buscava ampliar-lhe as dimesões, para justificar seu entusiasmo, encontrando nele qualidades que hoje, sob outra perspectiva, não é facil encontrar, uma vez desaparecido o lastro que lhe dava firmeza e projeção. A boa acolhida que lhe dera o ensaista e o rasgado elogio explicam em boa parte o curso posterior do romance, assim como o renome e a fama de que veio a gozar, impondo-se como fonte e modelo, logo mais, no entanto ultrapassado.

No desnorteio geral da ocasião, A Bagaceira conseguiu definir rumos, apontar caminhos ao renovar um dos veios mais ricos da ficção 
brasileira, o regionalismo, a partir de então regionalismo do Nordeste. Bastava-lhe esta função para justificar o prestígio que alcançou e o merecido reconhecimento. De fato, tornou-se um marco na história da Literatura Brasile:ra, definindo uma significativa passagem de época.

Colocava-se, e isto era de grande importância, numa posição chave entre o que existia e o que viria a existir Acenando com o preenchimento do vazio a que se aludiu, $A$ Bagaceira, de certo modo, apagava a memória do passado, curta demais entre nós e encobria ou fazia esquecer a imensa dívida que mantinha com a linhagem regionalista, que somava então, pelo menos cinquenta anos ( $O$ Sertanejo, O Gaúcho - 1970 e $O$ cabeleira são de 1876) Nesta direção bastaria lembrar os nomes de Alencar, F Távora, Taunay, num primeiro momento; os de Rodolfo Teófilo, Domingos Olímpio, Afonso Arino, Manoel de Oliveira Paiva e Simão Lopes Neto num segundo lance para sentir de perto os pontos de contato e sucessão entre uns e outros, para saber que desde cedo vieram definindo a linhagem na qual se encaixa, ainda que com outra visão e outra perspectiva, A Bagaceira.

Mais próximo, no entanto, como fonte, modelo e incentivo, está Euclides da Cunha de quem J.A.A. aproveita vários elementos e colocações quando suas personagens e os traços mais salientes de sua psicologia e comportamento, a partir da observação do homem nordestino. ( $O$ fato de um trabalhar no plano da ficção e outro não, em nada altera os resultados) Os Sertões, em linhas gerais, dão ao nordestino, como traços essenciais, superstição e fatalismo, telurismo e servilismo, fidelidade e resignação, honra e família, paciência e vingança, religiosidade e misticismo. É de Euclides da Cunha, principalmente, a idéia de oposição entre interior e litoral, entre o "mestiço neurastênico do litoral", fraco, desfibrado e medroso, e "o sertanejo que é antes de tudo um forte", convertido por J.A.A. na oposição sertanejo-brejeiro. Aquele encarnando as virtudes duma "raça" forte, altiva e corajosa, digna e honrada, e este os atributos de fraqueza e covardia, carente de dignidade e altivez.

("O estudante comparou a mentalidade do engenho, resíduos da escravaria, os estigmas da senzala, esses costumes estragados com a pureza do sertão" A Bagaceira, 13ạ p. 55).

O sertanejo, e isto também está em Euclides da Cunha, é um homem carregado de virtudes que nem a fatalidade do destino, a impiedade da natureza e do meio conseguem destruir ou abater. Forja-se, por isto mesmo, o homem dotado de reservas e qualidades tão altas, capazes de arguer qualquer etnia, imagem que vem a constituir o fundo ideológico de $A$ Bagaceira. Por outro lado, o brejeiro, mestiço do litoral, é o homem aviltado, produto das senzalas, corro do pelo en- 
genho e destituído até mesmo de condições para reagir ao seu processo de esmagamento e anulação humana. Aquele um homem livre, este um prisioneiro.

Esta oposição, radicalizada pela obra, falseia o quadro geral. Mesmo aceitando o pricípio de simpatia com que o A. elabora a figura do sertanejo e o carinho com que o trata, é preciso insistir em que nem o litorâneo é o escravo amesquinhado e covarde que procura mostrar, nem o sertanejo é tão livre e altivo quanto quer fazer supor. No recorte de sua figura atuam de modo dicisivo, tanto Alencar, idealizador do vaqueiro Arnaldo, quanto Euclides da Cunha, o divulgador das grandes virtudes sertanejas. Mais tarde, no campo da ficção, Graciliano Ramos, retomando aliás o vaqueiro descrito por Euclides, elaborava o extraordinário perfil de Fabiano, tão servo e servil, degradado e amesquinhado, quanto o mestiço litorâneo. Desfazia, assim, os equívocos, deixava de confundir aparência com a realidade mais funda, cortando rente a idealização de J.A.A., usando a mesma "mentira" da ficção.

Apesar desses deslocamentos de dados, A Bagaceira, resultante das preocupações regionalistas da época, retomava aqueles componentes e fazia-os retornarem à literatura para dar força nova a uma vertente que já parecia cansada e mesmo esgotada. Ajuda deste modo a compor o quadro de forças que atuam no rompimento do marasmo e na busca de novas soluçôes literárias, que encontram no próprio ambiente do nordeste fonte temática de imensas possibilidades, como ficou demonstrado com o tempo.

Pouco afeito às teorias de fins do século passado, consciente de que o realismo-naturalismo não poderia conduzir a arte de boa categoria

("O naturalismo foi uma bisbilhotice de trapeiros. Ver bem não é ver tudo, é ver o que os outros não vêem"),

J.A.A. procuraria evitar a medição que impunham as posições teóricas decorrentes do naturalismo, infletindo para atitudes mais consequente com as tradições internas, geradas pela ficção brasileira. Deste ponto de vista, escapa em boa medida dos prejuizos colonialistas que ainda atuam na obra de Euclides da Cunha, ao se colocar numa posição "nacionalista" em que se podem incluir os defeitos de classe e a visão seletiva e distorcida.

De fato, pode-se dizer que é com $\boldsymbol{A}$ Bagaceira, naquele momento que o romance brasileiro finca pé na realidade local, reablitando a perspectiva interna, meio apagada, no seu modo de enxergá-la e propôla em arte. Com isto pretendo dizer que não são apenas os aspectos da realidade brasileira que ingressam no romance, mas também um 
jeito brasileiro de considerá-los. Fruto de uma tradição histórica interna, nascida da necessidade de exprimir o país e suas peculiaridades, já não é o exclusivismo da óptica européia que modela o regionalismo de forma absorvente, forçando o aparecimento de uma maneira própria de encarar este universo. Há paradoxalmente uma libertação e uma prisão. $\mathrm{O}$ ato narrativo se torna menos sujeito às leis que o conduzem, mas a necessidade de exprimir a região ata o escritor ao comprom:sso de refletir seu mundo.

Jogando com estes dados, é possivel afirmar que J.A.A. vai mais longe do que Euclides da Cunha. Ônus da época, este ainda examina a realidade sertaneja pela perspectiva européia e, por azar, no exato momento em que se re nstaurava o colonialismo cultural como substituto do colonialismo direto, como forma de manutenção da estrutura consagrada pelas formas de domínio. Deste pecado J.A.A. se salvou.

E com A Bagaceira, mais por instinto que por razão, e isto é positivo, que o mundo tropical com sua luz e calor, suas cores e odores, seu enorme poder de ação e impulsão sobre o indivíduo entre para a ficção de modo decisivo. Não seria demais insistir que é um romance que procura - pede-se discutir se de modo feliz ou não - seu meio, sua gente e sua circunstâncias, o que só em parte e de modo demasiado precário fizeram os regionalistas anteriores.

Ve-se, a partir daí, que ele abre um grande rol de poss bilidades, no campo temático, cujos resultados não se fazem esperar. Descontando-se a dose de idealismo romântico que alimenta o texto e impede revisão mais acurada e crítica do contexto, o romance contém os elementos que permitem falar numa firme denúncia da realidade política, humana e social do nordeste, visto ainda ancorado numa estrutura arcaica, num sistema medieval de relações, onde sobressaltam as injustiças, as desigualdades, os privilégios, a fome e a miséria, o arbítrio e a prepotência, o mandonismo e o servilismo. Se é verdade que lhe falta maior fôlego para penetrar mais a fundo neste sombrio quadro, revolvendo-lhe as causas, e principalmente aderindo ao objeto de que fala, não se pode negar que aberta por ele a via, o aprofundamento virá logo a seguir com outros regionalistas, em especial com Lins do Rego e Graciliano Ramos, para desaguar no ponto mais alto de sua representação simbólica, que é Grande Sertão: Veredas.

A Bagaceira estabelece, assim, uma ponte entre o passado e o futuro, propondo-se como passagem de um para outro, despertando nova forma de enfoque. Se ainda tem cheiro de Alencar, não de:xa de ter pena que em tão raros momentos, sabor de Guimarães Rosa.

Romance de importante função histórica na Literatura Brasileira pelo que continha e desencadeou, apresenta no entanto, limites e de- 
ficiências sobre os quais pesam reservas que já podem ser descortinadas, sem despertar zelos ou ciúmes.

Comparado a Macunaíma (apenas para tomar obra do mesmo ano de publicação e de sua linguagem), $A$ Bagaceira deixa a impressão de coisa do passado, tanto pela forma de tratamento da matéria, quanto e sobretudo pela linguagem, ainda obediente ao critério de seleção hierarquizante de palavras, umas dignas outras não de entrar na obra. Neste sentido deixa-se pautar pela velha tradição da ficção brasileira, onde é sensível o tom oratório, utilizando o instrumento que fala do objeto sem participar de seu universo, da experiência que o define e lhe dá corpo. Não logra por isso ultrapassar a periferia dos problemas, contemplando-os a certa distância. Fala deles mas não pode partilhar de seu espírito por que não está com eles. Há um impedimento natural que frustra a possibilidade de transpor o espesso muro entre o homem sensível que enxerga, até demais para sua época, e as raízes dos problemas vistos.

Hoje, cinquenta anos depois, enquanto Macunaima vai sendo descoberta em sua imensa potencialidade e riqueza, numa prosa de recursos que se valorizam dia a dia, $A$ Bagaceira se parece uma relíquia de que a lembrança se esfuma, tornando difícil reconhecer a grande obra que descortinou o regionalismo dos anos trinta, sua qual dade e categoria. Isto se deve em especial à perspectiva adotada na construção do romance, que é a do passado, tanto pela linguagem utilizada, quanto pelo modo de conceber a própria arte.

Um dos grandes anseios modernistas era encontrar uma linguagem que expressasse com mais rigor e propriedade e realidade que nos cercava, o mundo de nossa relações. Este anseio visava a superar a barreira entre velho e novo para ultrapassar aquele conceito de arte fundado na seleção hierarquizante de palavras, que se distanciava do mundo objetivo e próximo, excluia os componentes do cotidiano, o considerado menos nobre. Desejava-se outra forma de tratamento do material linguístico, o que só poderia ser dado pela utilização duma linguagem liberta de preconceitos, por forma diversa de opção.

Ora, a obra de J.A.A., infelizmente, ainda preserva aquela dicotomia que permite ver no texto, em primeiro plano, a fala do escritor, de uma classe de letrados, a que se supõe a fala do povo, da maioria, exercitada pelas personagens que o representam. Fica nítido desde aí um critério de diferenciação entre a classe dos homens de bem, a que naturalmente pertence o autor, e os outros, a ralé, como ele mesmo chama. Essas duas linguagens se opõem da mesma forma em que se opõem as classes de seus falantes. De um lado os mandantes, senhores de uma linguagem mais polida, bem tratada e 
cultivada, de outro, o povo com sua "linguagem errada", e como ele carente de disciplina.

Consciente ou não desta colocação, e isto só tem relativa importância, o Autor fornece bem a idéia do mundo dividido entre os possuidores e os despojados, prolongando o esquema trazido e imposto pelo colonizador, no século XVI, e mostrando que ele resiste e se revela com clareza, sempre que aparece oportunidade.

Onde esta separação se torna bem sensível é no diálogo, cujas expressōes populares, menos cuidadas, aparecem como uma espécie de fala intercalada na linguagem do narrador que dá a voz ao interlocutor como mais uma concessão ou como curiosidade no aproveitamento de suas expressões. Mantém-se deste modo a distância com o fim de marcar a diferença entre ambos, para evitar compromisso com a algaravia dos falantes de cuja realidade cultural não partilha, embora possa até admirá-la e apreciá-la, o que aliás não é singular.

A fala das personagens, e em mais de um momento tem apenas esta função, é utilizada como modo de introduzir as expressões de gosto popular, porque da própria perspectiva do autor constituem outro mundo, outra realidade que ele aprecia mas não assume, mantendo-se afastado. Deste modo, ao distanciamento que existe naturalmente, por força da estrutura social, se materializa no romance por força das opções do escritor, de sua linguagem. Não me venham dizer que isto é conquista técnica, cuja grandeza estaria exatamente na capacidade de isolar os dois níveis, mostrando-os impenetráveis e incociliáveis.

O seguinte trecho pode ser visto como bom exemplo do que venho afirmando:

"Todos rotos, sem fundilhos, nas indecências da nudez vulgar.

Rezingavam nuns violentos apelos à nosologia popular:

- Molestado!

- Gota serena!.

Ou então corrompiam a fonética para requintar o insulto. Latomia, sempre brigão, alardeava:

- Eu estava canso de avisar. Mas o freguês tinha nó pelas costa, era cheio de noves fora. Aí, dei de garra do quiri. O bruto entesou. Aguentou a primeira pilorada - lepo! - no alto da sinagoga. Arrochei-lhe outra chumbergada. Aí, ele negou o corpo, apragatou-se, ficou uma moqueca. E veio feito em riba de mim. Arta, danado! Caiu ciscando, ficou celé!. Foi pancada de morte e paixão. Vá comer terra!.. Fugiu na sombra e levou um tempão amocambado." (A Bagaceira p. 54). 
Parece que a concessão de voz à personagem tinha como finalidade maior dar-lhe oportunidade de introduzir termos de seu universo, devidamente corrig:do, que o escritor não queria ver confundido com sua própria linguagem. Outro era seu mundo outro tinha de ser sua forma de representá-lo.

Ao contrário, pois, do que pode parecer, não há participação, universo solidário, mas distanciamento, separação. Sobrexiste um impedimento natural e profundo que os mantem afastados, talvez até mesmo inconscientemente, uma vez que a estrutura dominante é fruto duma vertente histórica que amoldou os homens ao seu modelo. Herdeira duma tradição de fundo med:eval peninsular, esta tradição incorpora a linguagem como componente de primeira ordem na preservação e defesa da ideologia conservadora. Embora se pressinta a simpatia do escritor aos homens deste plano, a exercício cultural em que se forjou não lhe permitiu ainda despreender-se da visão classista, onde o povo não entra nem conta, postando-se como tardio prolongamento da atitude compensatória que marcou entre nós o intelectual colonial, de que nem Euclides da Cunha conseguiu salvar-se.

Mesmo abrindo novos caminhos, como fez, a sua linguagem continua amarrada a preconceitos duma certa tradição, sem que ele ouse ultrapassar os estereótipos que a literatura cultivou, continuando assim a separação palavra-mundo, sentidos e traduzidos como entidades inconciliáveis. Talvez eu consiga ilustrar, com o seguinte exemplo, alguma coisa, do que venho dizendo. E um trecho em que se fala de Valentim, pai de Soledade, quando tangido pela seca se vê obrigado a encostar do engenho Marzagão:

\section{"Parecia,}

diz o narrador,

que ele nutria um empenho intencional na evocação da tragédia. Queria reconstruir seu passado sanguinário, como se servisse de escarmento aos apetites ruins que lhe rondavam, visivelmente, 0 lar provisório" - A Bagaceira, p. 33).

Para me deter apenas num dado, deixando outros de lado, veja-se bem como soa terrivelmente mal a palavra lar nesse contexto. $\mathrm{Na}$ verdade, tanto a palavra como seu referencial constituem elementos abstratos de cuja realidade não participa a personagem. E isto lembra o "Eva viu a uva" de que fala o educador Paulo Freire para atacar as formas de alfabetização que se utilizam de conceitos que não partilham do mundo do educador, mas aqui se trata duma visão por dentro que remexe a fundo as coisas. Na verdade LAR é palavra de conotações específicas e digna o alojamento de quem tem comida, 
cama e sexo regulares, de quem espia através da janela da casa grande o que se passa lá embaixo. Dar este nome ao barraco onde se encostou por uma fatalidade na natureza o retirante, é violentar seu mundo, incorrer em visão que conduz à mutilação e nega aquilo que em princípio parecia ser sua intenção.

Daí minha afirmação de romance retórico, sufocado pelo conceito vernaculista de linguagem, à tradição do bem falar o que lhe torna distante o universo que busca construir, de:xando claras as figuras entre objeto e intenção. Assim a disjunção do mundo objetivo acaba por se estruturar, inconscientemente na obra que fica longe de seu objeto.

Para atingir essa conqu.sta será preciso esperar a:nda algum tempo. Será preciso esperar pela obra de Lins do Rego e Graciliano Ramos para ver-se incorporada no sistema expressivo do escritor a fala das personagens, a fala comum quando desaparece o distanciamento entre ambos e se opera a comutação. Quando a linguagm passa a ser vista como bem comum, não como instrumento de comunicação que serve apenas a um grupo. Isto é, a partir do instante em que o homem do povo, o marginal social passa a ser visto como ser com direito a participar da vida e com consciênc:a desse dire.to, não por obra da concessão do homem culto que dele se apieada, mas por uma conquista do espaço próprio o que implica reconhec.mento de sua condição humana.

Não é difícil, entretanto, sustentar o princípio de que quem abriu cam.nho foi José Américo de Almeida. Não se contesta sua primazia, nem sua importância histórica enquanto agente catalizador, mas vista da perspectiva atual sua obra está mais para o passado do que para o presente. E creio que já é chegado o momento de ressaltar este componente sem melindres e sem azedume. Desempenhado o papel histórico que lhe reservaram as circunstâncias e a importância do momento é preciso ver com mais justeza e critério.

Antes de ir mais adiante, ainda dois aspectos relativos à expressão,à opção linguística, tendo em mente o intuito de aprofundar a descoberta das raízes que matizam o comportamento do escritor Ao falar do baile dos brejeiros, assim o descreve o narrador:

"Meninotas como mulheres feitas, com os peitos apojados de feminilidades indiscretas que lhes escandalizam a própria inocência. Mulatinhas de lábios roxos, como se tivessem sido mordidos, vivas e engraçadas, à espera do amor putrefatório. E as negritas oleosas, borboletas escuras, com cravos vermelhos no seio, como a carne acesa em brasa" (A Bagaceira, p. 40). 
Mesmo desculpando-se a tendência do Autor de intencionalmente depreciar o brejeiro para valorizar o sertanejo, ainda assim a linguagem resvala pelo preconceito, aflorando sorrateiro por entre as palavras. Do modo como está colocado o problema fica a impressão de que o povo é desprezível e de que ele é o único culpado de sua miséria, de sua desgraça, de sua condição. $O$ tom pejorativo explícito nos diminutivos faz as pessoas parecem vulgares e boçais. Mais que isto, causa e não produto da situação, levando o leitor ao mesmo processo de descaso por elas.

Extremada, esta posição leva a identificar a visão do romancista com a de Monteiro Lobato ao criar a figura do Jeca Tatu, quando fez o caboclo resumir todas as mazelas sociais de uma estrutura emperrada, injusta e arbitrária, administrando nele a soma da preguiça imemor:al que a cultura européia de fins do século passado distilou nos intelectuais brasileiros. Assim se pagava, e J.A.A. não está a salvo, o tributo da nossa cond.ção de intelectual periférico.

Nesta perspectiva se encontra a decantada indolência do povo brasileiro, como reflexo daquela posição, que é o que transparece nesta passagem:

"Nenhum agenciava melhor sorte. $\mathrm{Na}$ área da fartura, na gleba munificente, propícia a todas as culturas, essa gente vegetativa de uma passividade fatalista, afeita à lida de sol a sol, não plantava uma rama de batata à beira do rancho"

A passagem toda insiste nesta indolência, na falta de iniciativa, deixando transparecer um estado de preguiça crônico, sem oferecer no entanto dados suficientes para se compreender as razões mais profundas que favorecem um tal estado de coisa. Antes de Monteiro Lobato, já Graça Aranha em Canaã havia levantado o mesmo problema ao insistir na preguiça, na incapacidade de ação dos brasileiros, no seu caráter refratório a atividade sistemática.

Mas esta atitude tem seu lado positivo. Mesmo recusando-se a encampar a linguagem popular, deixando claro que não é a sua, José Américo a traz para o discurso literário, permitindo-lhe sentir toda a potencialidade e riqueza. Ainda que por tabela, indicou o cam:nho a seguir, entremostrando virtualidades apenas pressentidas.

E preciso ainda reconhecer que há momentos, pena que raros, onde a poesia contamina o texto, dando-lhe enorme força e surpreendente beleza. Isto ocorre principalmente quando sua linguagem logra romper a expressão aguardada e previsível para revelar-se e revelar, como nesses pequenos exemplos: 


\author{
"- E foi a seca que me deu coragem. Porque saber so- \\ frer, moço, isso é que é ter coragem" ( $A$ Bagaceira, 27)
}

ou quando diz:

$$
\begin{aligned}
& \text {.. ninguém é olho d'água pra viver revendo... (idem, } \\
& \text { p. 10). }
\end{aligned}
$$

onde a simplicidade impõe efetiva carga de sentido, imprimindo-lhe certa tonalidade roseana. Atingindo a sensibilidade sem elementos de mediação, a oralidade da frase encontrada imediato acolhimento.

E mais que sabido que um dos alvos do modernismo era a ruptura com o passado. Para realizá-la, no entanto, era preciso a doção de uma linguagem com força suficiente para quebrar as resistências e fundar uma nova maneira de ver, sentir e dizer. Examinando-se de perto seu estilo, chega-se logo à conclusão de que muito pouco acrescentou neste sentido, ficando mais perto do já sancionado. Na verdade, J.A.A. é defensor de uma linguagem nobre sob o pretexto de que ao artista cabe disciplinar:

"A língua nacional tem rr e ss finais... Deve ser utilizada sem os plebeismos que lhe afeiam a formação. Brasileirismo não é corruptela nem solecismo. A plebe fala errado; mas escrever é disciplinar e construir.

Esta forma de pensamento está subordinada exatamente àquilo que se quer combater, o legado do passado, que sempre travou o desenvolvimento duma linguagem mais próxima do falar da plebe, uma linguagem que fosse, ela própria, a expressão daquele universo e não sua contradição. Felizmente a intuição do artista que havia no escritor permite-lhe, mais de uma vz, romper a camisa de força dos preconceitos e convenções para deixar aparecer ainda que indireta e inconscientemente, a "linguagem errada do povo" que luta contra a idéia de casticismo e pureza linguística, contra o princípio do conservantismo, inerente a toda atitude de defesa da imutabilidade da língua.

Para disciplinar e construir, antes que corrigir a língua do povo, é preciso chegar a ele e isto se faz utilizando a mesma línguagem que ele fala, a realidade de que ele participa, longe das abstrações que não lhe dizem nem podem dizer nada. Ainda uma vez, esta foi outra das grandes descobertas de Paulo Freire, o educador voltado para a realidade circundante, para o mundo de suas relações. Fo: por isto mesmo capaz de disciplinar e construir, porque jogou com os dados do contexto que lhe era conhecido. (Não se vá entender a partir daqui que toda obra literária supõe a linguagem do povo, que seja concessiva e de fácil acesso) 
Mas é preciso desdobrar o livro para enxergar também outros aspectos.

A composição do romance, como já observou Cavalcanti Proença, obedece ao princípio da justaposição de capítulos, de cenas isoladas com que objetiva uma forma de mimese da realidade do nordeste, relativamente ao homem e à paisagem, através de quadros que formam um certo painel desse universo. Falta-lhe, no entanto, um processo de travamento mais bem articulado para permitir enxergar com clareza seus lineamentos, sua unidade e principalmente a sequência em que decorrem os acontecimentos.

Daí uma primeira conclusão.

A impressão de permanência, de estagnação ressalta a impropriedade com que o tempo é manipulado pelo escritor. Não existe uma sensação de duração, de pontos de referência. A passagem do tempo não deixa marcas, que imprimam a notação de que as coisas realmente decorreram em certo prazo, de tal modo que se chega ao fim com as mesmas marcas do início, dada a contiguidade e imediatez das notações. Fato que se reflete principalmente na construção das personagens.

Sendo assim e com o fim de suprir as deficiências de montagem e articulação, o narrador recorre com frequência ao descritivismo, à informação indireta para poder completar o retrato da imagem que não teve condições de ganhar corpo, de se consumar por si mesma e impor-se como criatura, que desse a ilusão de ser inteiriço. Às personagens falta densidade e autonomia de ação e com isto apresentamse carentes de profundidade e de capacidade para responder pelos que lhes quer atribuir o romancista. Daí não raro a sensação de falsete que, mesmo na economia interna do romance, fica difícil aceitar, dada a fragilidade da construção.

Para exemplificar bastaria lembrar o caso de Lúcio em cuja capacidade de ação e idealismo muito se insiste, quando na realidade ele nem age nem se define, permanecendo o mesmo de princípio a fim, de tal modo que o narrador vê obrigado a recorrer a vários expedientes para completar a informação, em especial ao discurso indireto, como aqui:

"O ambiente preguiçoso não se lhe comunicava ao temperamento árdego e cioso de ação",

quando na verdade, nada denuncia a suposta ação, nenhum ato justifica as qualidades que o A. parece querer atribuir-lhe. 
A grande dificuldade do romancista na criação da personagem está exatamente na transposição dessas idéias. Não me é suficiente pensá-la duma certa maneira se no momento de sua realização as palavras não conseguirem fazê-lo como eu a imaginei, obrigando-me ao desdobramento, a tentativa de suprir as deficiências. O impacto causado no leitor tem de ser consequência natural da desenvoltura da personagem sem intermediação de nenhuma natureza.

A cena, ou encenação, em que Lúcio tenta matar Soledade, para ficar no exemplo desta personagem, bastaria dizer que é ridícula e em nada convincente. Por mais razão que assista à personagem, por maior que tenha sido seu choque e sua decepção ao saber que sua amada tenha se convert.do em amante do pai, falta-lhe envergadura para ação, falta capacidade o autor para construir o miolo em que repousa o desenvolvimento dos dramas humanos. E preciso então recorrer ao expediente da informação para completar o quadro numa evidente mostra de desconfiança do próprio autor em sua realização. Com pequenas mudanças isto se pode dizer de todos os outros personagens, salvo talvez de um deles.

De fato, existe um personagem que, talvez por não ser de prmeira plana, apresenta rasgos de autenticidade e coerência, encarnando com propriedade as virtudes atribuídas ao sertanejo. Trata-se de Pirunga, o fiel amigo de Valentim, e defensor de Soledade. Permanecendo na penumbra dos acontecimentos sua presença deixa profundas marcas na ação do romance, sem necessitar de muletas para se amparar. E que sem ter maiores compromissos a personagem pode ficar solta e assim desenvolver-se sem constrangimentos, sem preocupação de provar isto ou aquilo, sem ter atrás de si a marcação rígida do leitor para cobrar-lhe as promessas.

Doutra parte, não se pode deixar de enxergar por detrás de Pirunga a figura do vaqueiro Arnaldo, o super-herói de $O$ Sertrnejo, de Josë de Alencar, que indiscutivelmente funciona como paradigma. Até mesmo o cavalo Corisco lembra de perto o romance de Alencar com cenas de incrível semelhança. José de Alencar foi leitura preferida de J.A.A., com quem tem ainda outros pontos de contacto. Os dois ostentam pos.ção moralista e se ligam ao mito da pureza sertaneja; ambos creem nas soluções vindas dos senhores, e, pois, no patriarcalismo "esclarecido" ou não. Ao lado de A Bagaceira, o escritor demonstra preocupação em exemplificar o comportamento, segundo os podrões morais da ideologia dominante, o que expl.caria o castigo como pun:ção tanto de Soledade quanto de Dagoberto, abrindo o romance para atitude de catarse que realmente não lhe fica bem. 
Mas posso também inverter a posição e dizer que 0 romance neste sentido se realiza plenamente porque logra apreender com exat.dão as coordenadas em que se estrutura a sociedade brasileira com toda a sua falsa moralidade. Acho que se pode fazer também este tipo de leitura que se infunde no romance por uma espécie de pressão natural do próprio meio que busca mimetizar, e se infiltra na construção a despeito de se querer ou não. Não creio, no entanto, que seja a mais correta das leituras.

Sempre ressalvando a procedência de J.A.A., como descortinador e pioneiro, nunca é demais aproximar a personagem Dagoberto, "homem brutificado pelo trato semibárbaro do engenho", de Paulo Honório, personagem de São Bernardo também brutificado pelo ofício, também produto do meio e da mesma espécie de engrenagem que a todos nivela pelo mesmo padrão. Mas enquanto Paulo Honório alcança a mais convincente verticalidade envolvendo a tudo e a todos, assumindo dimensão raramente atingida na ficção brasileira Dagoberto parece um boneco vazio, uma caricatura. Da presença do primeiro é impossível ficar-se ou sair-se indiferente, do segundo é difícil guardar-se alguma coisa.

E já que tocamos no nome de Graciliano Ramos, valeria a pena levantar outro problema, de extrema importância, de que J.A.A. foi ao que tudo indica precursor na novelística brasileira: a substituição do nome da personagem pela sua condição ou simplesmente pela falta de nome, conforme observou Wilson Martins ( $A$ Literatura Brasileira - $O$ Modernismo - São Paulo, Ed. Cultrix, 1965, vl. VI, p. 264): o patrão, o retirante, o soldado, o capanga, o capataz, enquanto os animais, regra geral, tem nomes próprios, o que ajuda a por em evidência a estrutura e seu sistema de valores. As pessoas são aquilo que sua situação e condição mostram: os que tem e mandam e os que não tem e, portanto, não são ressalvados os animais que tem identidade e se particularizam no meio, por serem a prova do poder dos primeiros, por guardarem distância e independência.

Ora, a ausência de nome foi uma das formas encontradas por Graciliano Ramos como auxiliar poderoso no desvelamento da estrutura político-social, a fim de desmascarar sua forma mais aguda de agressão, de aviltamento e degradação do homem. Ao elidir o nome das criaturas ele elimina a própria condição humana da pessoa, rebaixando-a à situação animal. Essa conquista do regionalismo tem de ser creditada a J.A.A. tenha ele tido consciência e intenção ou não de o fazer, sua intuição do problema reflete a capacidade de apreender $o$ contexto histórico onde a ocorrência do fenômeno aparece como traço peculiarizador que distingue aquela estrutura e define seu sistema de atribuição de valores. Pode-se dizer, retomando suas próprias palavras que aqui ele conseguiu ver onde poucos viram. 
Nesta direção J.A.A. mostrava na ficção brasileira as imensas poss:bilidades temáticas que o Nordeste oferecia, com as contradições que resumiam a natureza mais grave dos problemas brasileiros: as carências e sobras, excessos e zelos, anseios e frustações, mitos e misérias. Ele tomou um dos aspectos que permitiam ressaltar o rol destas contradições. Embora em si mesma ela esteja ausente, o romance é da seca, por força da qual aqueles problemas se evolumam fazendo aflorar os sentimentos destintivos de sua gente: o sentimento de honra e família, como já havia feito Taunay e, depois Euclides da Cunha; o apego à terra apelo mais forte do sertanejo, que, periodicamente expulso, está sempre à espreita do momento oportuno para retornar ao espaço de suas afeições. Este telurismo se constituirá na marca mais profunda do regionalismo posterior a J.A.A. e juntamente com a sexualidade e o instinto, resignação e fatalismo, se transformarão em traços definidores deste homem e deste meio.

Hoje isto tudo parece lugar comum, tanto foi usado e desgastado, mas nunca é demais lembrar que foi somente depois da publicada $A$ Bagaceira que tudo isto se tornou moeda corrente.

Embora de modo não inteiramente feliz, o romance aparecia com forte teor social denunciando a emperrada e arcaica estrutura nordestina de que está frase, dita pelo patrão ao despedir um de seus "empregados", pode fornecer em boa dose a medida:

$$
\text { “- O que está na terra é da terra!” (p. 10), }
$$

e que se poderia completar, dizendo, inclusive as pessoas. Esse teor medieval no sistema de relações e posse está presente até hoje na região, embora não seja apenas apanágio dela.

A denúncia do servilismo e da escravidão abriu o caminho para sua visão e exame, mas não teve o impacto que merecia, porque foi amenizada por um processo catártico de fundo moralizante, aceito como capaz no encaminhamento e solução dos problemas: a modernização do engenho pela introdução dos princípios da técnica que assim permitiriam a exploração do mito da terra fértil que somente não produzia em grande quantidade porque os processos de operação eram arcaicos. $\hat{E}$ nesse momento que interfere romanticamente $\mathbf{o}$ personagem Lúcio, o bacharel, filho de senhor de engenho, que se reintegra à terra para dotá-la de outros e mais eficazes modos de produção. Procedendo à remodelação e reformulação do engenho Marzagão, segundo diz o narrador, ele oferece aos trabalhadores nova vida e nova condição de realização abrindo espaço para o ato consciente e caminho para a libertação.

Esta idealização seródia, mesmo para os anos 30 , evidencia o aspecto romântico do problema, tratado com sabor passadista. Já 
no começo do século, Euclides da Cunha tinha feito sentir que os entraves a qualquer mudança estavam no sistema, na estrutura social arcaica, que ciosamente defendida pelos donos da terra, permanecia inalterada. O esforço individual, isolado, nada podia contar a força do meio, contra a obsessiva e arcaica idéia de posse.

Aliás não foi necessário aguardar muito tempo para mostrar que a posição de J.A.A. era retórica inviável. Pouco depois, José Lins do Rego desmontava suas teses, mostrando que a chegada da técnica através da implantação da usina, antes que resolver, só fez agravar os problemas e, numa obra extraordinariamente bem realizada, São Bernardo, Graciliano Ramos põe abaixo a mística do progresso técnico quando seu emprego se faz sem modificação da estrutura que lhe dá amparo. Manobrada por indivíduo, que se utiliza do sistema para empregá-la, a técnica é forma mais pesada de escravidão. Pior ainda para os subdesenvolvidos, outra forma de dependência .

Feito este levantamento, já é hora de tirar algumas conclusōes.

Suprimidas as coordenadas em que foi escrita e apareceu para o público, A Bagaceira perdeu muito de seu encanto e de sua força. Estimulou grande número de escritores e obras que, melhor realizadas, a foram deixando na penumbra, ultrapassando suas propostas e fazendo-a envelhecer Embora seja fácil hoje em dia fazer-lhe restrições, é preciso reconhecer que foi por seu intermédio que a ficção conquistou novo espaço, prestando enorme serviço à cultura brasileira. Não só aludiu ao processo de deslocamento das formulações intepretativas do Brasil, mas iniciou um meio eficiente para permitir sua realização ao mostrar como proceder. 